\title{
The effect of the COVID-19 pandemic on mental health calls for police service
}

\author{
Jacek Koziarski*i(i)
}

\begin{abstract}
Drawing upon seven years of police calls for service data (2014-2020), this study examined the effect of the COVID-19 pandemic on calls involving persons with perceived mental illness (PWPMI) using a Bayesian Structural Time Series. The findings revealed that PWPMI calls did not increase immediately after the beginning of the pandemic in March 2020. Instead, a sustained increase in PwPMI calls was identified in August 2020 that later became statistically significant in October 2020. Ultimately, the analysis revealed a 22\% increase in PwPMI calls during the COVID-19 pandemic than would have been expected had the pandemic not taken place. The delayed effect of the pandemic on such calls points to a need for policymakers to prioritize widely accessible mental health care that can be deployed early during public health emergencies thus potentially mitigating or eliminating the need for increased police intervention, as was the case here.
\end{abstract}

Keywords: Police, Mental Health, COVID-19, Bayesian Structural Time Series

\section{Introduction}

In March of 2020, the World Health Organization declared Coronavirus Disease 2019 (COVID-19) as a pandemic (World Health Organization, 2020). Such major public health emergencies have the ability to foster feelings of fear, uncertainty, and loneliness due to increased risk of morbidity and death; public health measures meant to curb virus transmission, such as physical distancing, lockdowns, or quarantines; as well as possible or experienced unemployment, among other reasons (Fitzpatrick et al., 2020; Moreno et al., 2020; Rajkumar, 2020; Vigo et al., 2020; Vindegaard \& Benros, 2020; Xiong et al., 2020). These factors, either alone or in combination, can in turn translate into higher levels of psychological distress (Pfefferbaum \& North, 2020). In fact, since the onset of the COVID-19 pandemic, a broad body of literature has documented the detrimental effects the pandemic has had on mental health across

*Correspondence: jkoziars@uwo.ca

Department of Sociology, University of Western Ontario, 1151 Richmond

Street, London, ON N6A 3K7, Canada the globe. More specifically, numerous studies from Canada (e.g., Jenkins et al., 2021; Zajacova et al., 2020), the United States (Holman et al., 2020), the United Kingdom (e.g., Daly et al., 2020; Proto \& Quintana-Domeque, 2021), and elsewhere (e.g., Arendt et al., 2020; Rajkumar, 2020; Vindegaard \& Benros, 2020; Wang et al., 2020; Xiong et al., 2020) have reported either deteriorations in self-reported mental health or heightened levels of specific symptoms-such as post-traumatic stress symptoms (PTSS), stress, anxiety, and/or depression-among their respective general populations during the COVID-19 pandemic. Other studies that have examined the effects of specific public health measures on mental health have revealed similar findings. Rossi et al. (2020), for instance, identified high rates of PTSS, depression, anxiety, and stress among the Italian general population during lockdown; whereas Wang et al. (2021) found similarly high rates of depression, anxiety, and stress among individuals subject to quarantine measures in China.

Additional lines of inquiry have also examined the pandemic's mental health effects on specific sub-populations. Individuals with pre-existing mental health disorders, for instance, have reported increases in their original author(s) and the source, provide a link to the Creative Commons licence, and indicate if changes were made. The images or other third party material in this article are included in the article's Creative Commons licence, unless indicated otherwise in a credit line to the material. If material is not included in the article's Creative Commons licence and your intended use is not permitted by statutory regulation or exceeds the permitted use, you will need to obtain permission directly from the copyright holder. To view a copy of this licence, visit http://creativecommons.org/licenses/by/4.0/. The Creative Commons Public Domain Dedication waiver (http://creativeco mmons.org/publicdomain/zero/1.0/) applies to the data made available in this article, unless otherwise stated in a credit line to the data. 
Table 1 Descriptive Statistics, PwPMI Calls Per Week, 2014-2020

\begin{tabular}{|c|c|c|c|c|c|c|c|c|}
\hline Year & Min. & 1st Quartile & Median & Mean & SD & 3rd Quartile & Max. & Total \\
\hline 2014 & 2 & 7 & 11 & 10.7 & 4.2 & 14 & 22 & 568 \\
\hline 2015 & 4 & 8 & 12 & 11.9 & 4.4 & 15 & 20 & 628 \\
\hline 2016 & 0 & 6 & 8 & 8 & 3.1 & 11 & 14 & 429 \\
\hline 2017 & 1 & 7 & 10 & 9.8 & 4.3 & 12 & 22 & 520 \\
\hline 2018 & 3 & 7 & 9 & 9.7 & 3.5 & 12 & 18 & 515 \\
\hline 2019 & 4 & 9 & 11 & 11.4 & 3.3 & 13 & 19 & 602 \\
\hline 2020 & 4 & 10 & 13 & 13.5 & 4.7 & 18 & 22 & 715 \\
\hline 2014-2020 & 0 & 8 & 11 & 10.9 & 4.2 & 14 & 22 & 3977 \\
\hline
\end{tabular}

respective symptoms (Vindegaard \& Benros, 2020; Xiong et al., 2020), which have likely been additionally exacerbated for some due to disruption of in-person psychiatric care to accommodate public health measures (Moreno et al., 2020; Vigo et al., 2020). Healthcare workers on the frontlines have similarly reported heightened levels of stress, anxiety, and depression during the COVID-19 pandemic due to factors such as immediate exposure to the virus and death, concerns over infection of self and family members, lack of personal protective equipment, overwork, and burnout (Kock et al., 2021; Moitra et al., 2021; Mosheva et al., 2021). Emerging research has also identified that individuals who have recovered or are in-recovery after COVID-19 infection may experience depression or PTSS (Khademi et al., 2021; Vindegaard \& Benros, 2020).

Although evidence on the mental health effects of the COVID-19 pandemic is continuously building, research examining the effects of the COVID-19 pandemic on calls for police service involving persons with perceived mental illness (PwPMI) is scant. ${ }^{1}$ In fact, to-date, research examining the impacts of the pandemic on police-related activity has almost exclusively focused on crime (see e.g., Andresen \& Hodgkinson, 2020; Ashby, 2020; Buil-Gil et al., 2020; Campedelli et al., 2020; Estévez-Soto, 2021; Felson et al., 2020; Gerell et al., 2020; Hodgkinson \& Andresen, 2020; Langton et al., 2021; Payne et al., 2021; Piquero et al., 2021). While this area of inquiry is certainly important, crime only comprises approximately $20-30 \%$ of all police calls for service (Wuschke et al., 2017). As such, the effect of the COVID-19 pandemic on the remaining $70-80 \%$ of police activity-which includes PwPMI calls-remains relatively unexplored. Further,

\footnotetext{
${ }^{1}$ Mental health calls are often coded as such by responding officers due to a perception or belief that mental health-related issues may be present, as opposed to a certainty that they are present. In light of this, Frederick and colleagues (2018) recommend that empirical efforts which rely on officer-generated data should employ terminology that reflects this uncertainty.
}

even though the police have long been the first responders to PwPMI (Bittner, 1967), renewed debates around the role of the police in these calls warrants an investigation as to whether this role becomes more pronounced during a pandemic.

To-date, the only study to explore this area found that mental health-related calls ${ }^{2}$ in Detroit, Michigan decreased early in the COVID-19 pandemic (Lersch, 2020). This particular study, however, only drew upon call data through April 27, 2020. This is arguably too early in the pandemic to detect any significant changes in PwPMI calls, which may have increased as mental health deteriorated and in-person psychiatric care was disrupted in subsequent weeks and months. Further, Lersch's (2020) study is also largely descriptive in nature, meaning it is not optimal for detecting the impact of an intervention. Additional research with a more robust methodological approach is therefore warranted. In light of these existing limitations, the purpose of this study is to conduct a more rigorous examination into the effect of the COVID19 pandemic on PwPMI calls for police service with a longer time-series that extends to the end of 2020.

\section{Data and methods}

Data for this study were drawn from the computer-aided dispatch system of the Barrie Police Service in Barrie, Ontario, Canada and included all calls for service from January 1, 2014 through December 31, 2020 where the final disposition was 'Mental Health' $(N=3977)$. For the purpose of analysis, these data were aggregated at the weekly level (see Table 1). The first and last week in the series were dropped as they did not contain seven days, thus generating 364 total weeks for analysis.

To analyze the effect of the COVID-19 pandemic on PwPMI calls, a Bayesian Structural Time Series (BSTS) model was estimated. BSTS models are

\footnotetext{
2 'Suicide in Progress,' 'Suicide Threats,' 'Mentally Ill Person'
} 


\section{PwPMI Calls During COVID-19 Pandemic}

WHO Pandemic Declaration: Week of March 9, 2020

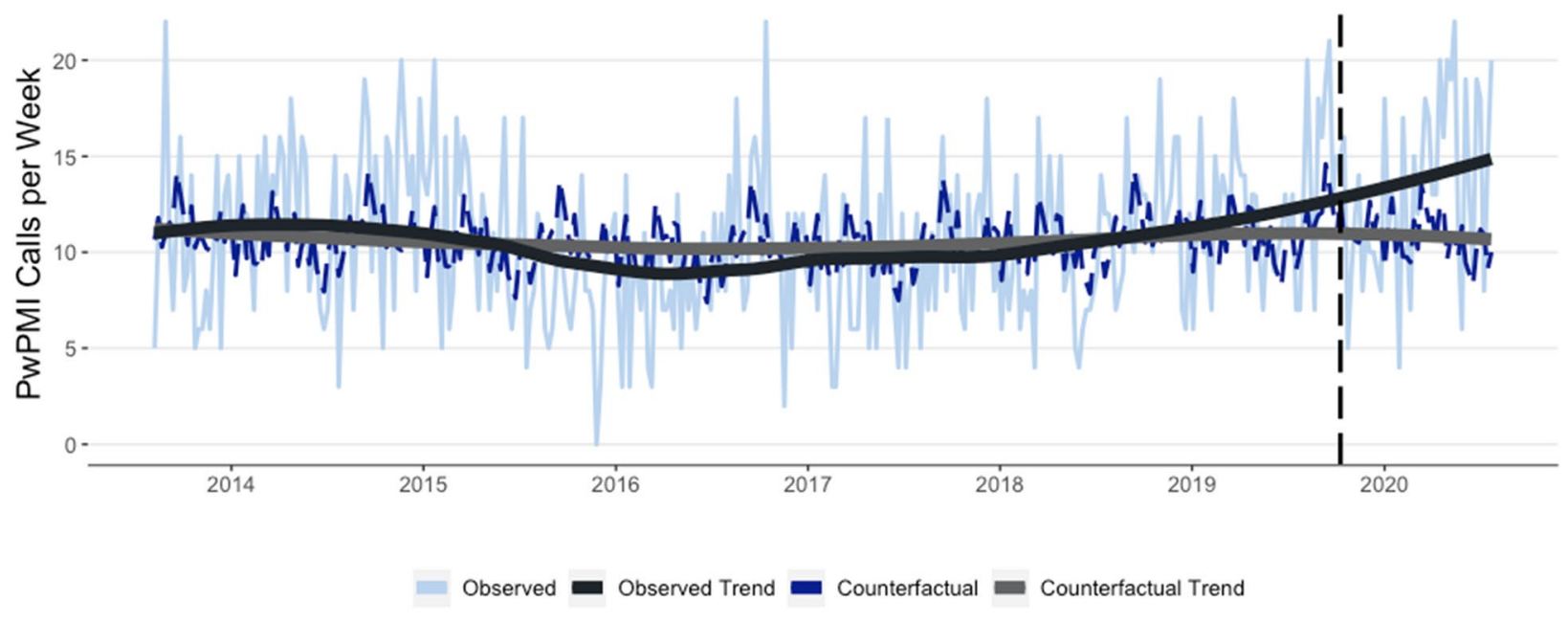

Loess Span $=0.60$

Fig. 1 PwPMI Calls During COVID-19 Pandemic

quasi-experimental in nature in that they measure the effect of an intervention by predicting a counterfactual time-series that would have occurred had the intervention not taken place (Brodersen et al., 2015). This counterfactual is predicted by drawing upon: (1) the prior and posterior behaviour of the time-series in question, and (2) contemporaneous covariates that were not affected by the intervention (Brodersen et al., 2015). Unlike crime, which is widely understood to fluctuate based on temperature-related mechanisms (e.g., Andresen \& Malleson, 2013; Linning et al., 2017), little is currently known as to what (if anything) is temporally associated with PwPMI calls. $^{3}$ As a result, the current BSTS modelling is univariate in nature. That is, the model was estimated solely using the prior and posterior behaviour of the timeseries. However, with 364 weeks in the series, an adequate BSTS model can be inferred in spite of a lack of theoretically-or empirically-informed covariates. Further, a seasonal term was included in the model to account for weekly fluctuations in PwPMI calls. The intervention was set to the week in which the World Health Organization declared COVID-19 as a pandemic (week of March 9, 2020), resulting in 323 pre-intervention weeks and 41 post-intervention weeks. Ten thousand Markov Chain

\footnotetext{
${ }^{3}$ The only study to temporally examine PwPMI calls concluded that "these variables [temperature and precipitation] cannot be expected to have a large magnitude impact on MHA [Mental Health Act] calls for police service." (Vaughan et al., 2019, p. 181).
}

Monte Carlo samples were drawn to obtain more robust inferences.

\section{Results}

Figure 1 displays the observed and counterfactual timeseries, along with their respective trends over time. Both time-series largely exhibited a similar weekly trend, but a divergence was noted immediately preintervention that is sustained and becomes more pronounced in the post-intervention period. ${ }^{4}$ A closer examination at the difference between the observed and counterfactual time-series post-intervention is displayed in Fig. 2. More specifically, in the weeks between March and July 2020, there appears to be no notable difference between the observed and counterfactual time-series. This, however, changes during the weeks

\footnotetext{
${ }^{4}$ As is evident in Table 1 and Fig. 1, there was quite a substantial drop in PwPMI calls in 2016 that the counterfactual time-series was unable to account for. Given the univariate nature of the present BSTS modelling, a sensitivity analysis was conducted to examine the influence this drop in PwPMI calls may have had on the final results. For this sensitivity analysis, the entirety of 2016 was removed from the time-series and weekly call counts from 2014 and 2015 were shifted into the fields for 2015 and 2016, respectively, to fill the 'gap' in the series. A BSTS model was subsequently estimated using this modified data. Findings of the sensitivity analysis revealed that $464(S D=32.06$, $\mathrm{CI}=400.8-525)$ PwPMI calls were expected during the post-intervention period, whereas the model with 2016 included estimated 457 ( $S D=32.57$, $\mathrm{CI}=393.9-520$ ) PwPMI calls during the post-intervention period (see Table 2). This suggests that the drop in PwPMI calls in 2016, and the inability of the counterfactual time-series to detect it, has almost no impact on the final results. To see the posterior inference table for this sensitivity analysis, please see the online supplementary material (Additional file 1).
} 


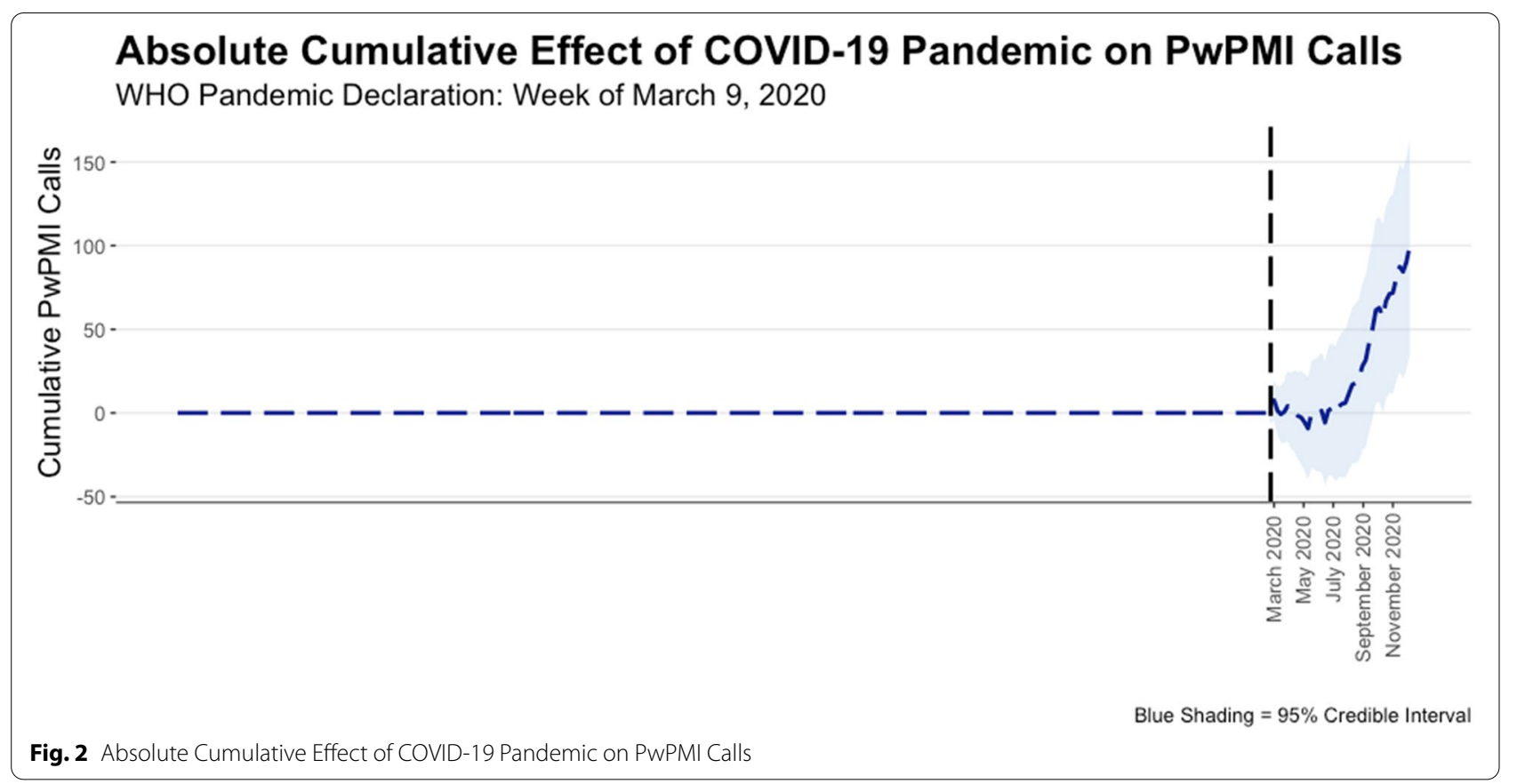

Table 2 Posterior Inference, Bayesian Structural Time-Series Model

\begin{tabular}{lll}
\hline & Average & Cumulative \\
\hline Actual & 13 & 557 \\
Prediction (SD) & $11(0.78)$ & $457(32.57)$ \\
$95 \% \mathrm{Cl}$ & {$[9.4,12]$} & {$[393.9,520]$} \\
Absolute Effect (SD) & $2.4(0.78)$ & $100.3(32.57)$ \\
$95 \% \mathrm{Cl}$ & {$[0.87,3.9]$} & {$[35.55,163.1]$} \\
Relative Effect (SD) & $22 \%(7.1 \%)$ & $22 \%(7.1 \%)$ \\
$95 \% \mathrm{Cl}$ & {$[8 \%, 36 \%]$} & {$[8 \%, 36 \%]$} \\
\hline
\end{tabular}

Bayesian One-Sided Tail-Area Probability: $p<.001$

Posterior Probability of a Causal Effect: $99.9 \%$

of August 2020 where the difference between the timeseries begins a sustained positive increase. Importantly, the 95\% credible interval plotted in Fig. 2 includes zero until October 2020. As such, the difference between the observed and counterfactual time-series can only be considered as statistically significant in the weeks of October 2020 or later.

Table 2 presents the posterior inference for the BSTS model. The model estimated that there would be a mean of 11 PwPMI calls per week during the post-intervention period $(S D=0.78, C I=9.4-12)$, however a mean of 13 was observed. In sum, during the entire 41-week post-intervention period, the Barrie Police Service received approximately $22 \%(S D=7.1, \mathrm{CI}=8-36)$ more PwPMI calls than was predicted $(n=100.3, S D=32.57$,
$\mathrm{CI}=35.55-163.1)$. The posterior probability of the BSTS model is $99.9 \%(p<0.001)$, suggesting that the COVID-19 pandemic was associated with a statistically significant increase in PwPMI calls for police service.

\section{Conclusions}

The purpose of the present study was to extend previous work into the examination on the effect of the COVID19 pandemic on PwPMI calls for police service. While the only previous inquiry by Lersch (2020) found that PwPMI calls decreased in Detroit, Michigan, their study design was largely descriptive in nature and only drew upon data through April 27, 2020. As such, Lersch's (2020) work was not optimally designed to detect the effect of an intervention, nor was the post-intervention time-series long enough to adequately measure the effect of the COVID-19 pandemic on PwPMI calls. The present study, therefore, sought to improve upon this work by employing a more robust methodological approach that drew upon a longer time-series.

The findings revealed that between March and July 2020 , there was no difference between the observed number of PwPMI calls and what would have been expected had the COVID-19 pandemic not occurred. In August 2020, however, the observed number of PwPMI calls began a sustained positive increase away from what was predicted by the BSTS model. This difference between observed and expected time-series later became statistically significant in October 2020 and ultimately accounted for a $22 \%$ increase in PwPMI 
calls relative to what was expected. In other words, this study found that the COVID-19 pandemic has had an effect on PwPMI calls for police service, but that the effect was not immediate. While it is difficult to point to any particular pandemic-related factor, or combination of factors, that may have contributed to the observed increase in PwPMI calls, it is worth noting that the study jurisdiction entered into the second wave of the COVID-19 pandemic in September 2020 after low COVID-19 case-counts and easing of public health restrictions over the summer months (Nielsen, 2020). Longitudinal studies into the mental health effects of the COVID-19 pandemic have found that heightened levels of anxiety, stress, and depression reported at the onset of the pandemic may be sustained over time (Czeisler et al., 2021; Vahratian et al., 2021), thus it is possible that the emergence of the second wave may have exacerbated mental health problems spurred on by the first wave to the point of requiring police involvement.

From a practical perspective, while the role of the police as responders to mental health issues in the community has been a highly-debated topic even before the COVID-19 pandemic (Thompson, 2010; Wilson-Bates, 2008)-and especially since the defund the police movement (Koziarski \& Huey, 2021)-it is clear this role has become more pronounced during the pandemic and thus will likely add to this debate. Fortunately, though, as the present study reveals, this more pronounced role did not begin until five months after the COVID-19 pandemic began. As such, this points to a need for policymakers to prioritize widely accessible mental health care that can be deployed early during public health emergencies. Doing so can possibly mitigate or eliminate the need for police involvement later on, as was the case here. If a response is required, however, and in-light of increasing calls for civilian-based responses (Watson et al., 2021), recent research warns us that calls for service which are initially reported as involving PwPMI may in fact encompass other components that would require a police response (Lum et al., 2021; Ratcliffe, 2021). Future work is therefore needed as to how the police can safely and appropriately triage PwPMI calls with their local mental health partners, and particularly so during public health emergencies which can lead to an increase in such calls. Additional research is also needed that replicates the present study in other jurisdictions, as is multivariate research that builds upon the univariate limitation of the current study. In doing so, a more thorough understanding around the effect the COVID-19 pandemic has had on PwPMI calls can be obtained.

\section{Supplementary Information}

The online version contains supplementary material available at https://doi. org/10.1186/s40163-021-00157-6.

Additional file 1. Sensitivity analysis, posterior inference table, Bayesian Structural Time-Series Model.

\section{Acknowledgements}

The author would like to thank Chief Kimberley Greenwood, Deputy Chief Rich Johnston, and Crime Analyst Paula Curry of the Barrie Police Service for providing the data used in this work. Additional thanks also go to Scott Mourtgos and lan Adams for sharing the R code that helped produce Figures 1 and 2, as well as to Jin Ree Lee for feedback on earlier versions of this manuscript.

\section{Authors' contributions}

The author is solely responsible for this work. Any expressed views are his alone and do not necessarily represent the views of the City of Barrie or the Barrie Police Service. The author read and approved the final manuscript.

Funding

No funding was used to support this work.

Availability of data and materials

The data are not available as they are confidential.

\section{Declarations}

Competing interests

The author declares that he has no competing interests.

Received: 23 April 2021 Accepted: 23 September 2021

Published online: 11 October 2021

\section{References}

Andresen, M. A., \& Hodgkinson, T. (2020). Somehow I Always End up Alone: COVID-19, Social Isolation and Crime in Queensland Australia. Crime Science, 9(1), 25. https://doi.org/10.1186/s40163-020-00135-4

Andresen, M. A., \& Malleson, N. (2013). Crime seasonality and its variations across space. Applied Geography, 43, 25-35. https://doi.org/10.1016/j. apgeog.2013.06.007

Arendt, F., Markiewitz, A., Mestas, M., \& Scherr, S. (2020). COVID-19 pandemic, government responses, and public mental health: investigating consequences through crisis hotline calls in two countries. Social Science \& Medicine, 265, 113532. https://doi.org/10.1016/j.socscimed.2020.113532

Ashby, M. P. J. (2020). Initial evidence on the relationship between the coronavirus pandemic and crime in the United States. Crime Science, 9(1), 6. https://doi.org/10.1186/s40163-020-00117-6

Bittner, E. (1967). Police discretion in emergency apprehension of mentally ill persons. Social Problems, 14(3), 278-292. https://doi.org/10.1525/sp.1967. 14.3.03a00040

Brodersen, K. H., Gallusser, F., Koehler, J., Remy, N., \& Scott, S. L. (2015). Inferring causal impact using bayesian structural time-series models. The Annals of Applied Statistics, 9(1), 247-274. https://doi.org/10.1214/14-aoas788

Buil-Gil, D., Miró-Llinares, F., Moneva, A., Kemp, S., \& Díaz-Castaño, N. (2020). Cybercrime and shifts in opportunities during COVID-19: A preliminary analysis in the UK. European Societies, 23(sup 1), 1-13. https://doi.org/10. 1080/14616696.2020.1804973

Campedelli, G. M., Aziani, A., \& Favarin, S. (2020). Exploring the immediate effects of COVID-19 containment policies on crime: An empirical analysis of the short-term aftermath in Los Angeles. American Journal of Criminal Justice. https://doi.org/10.1007/s12103-020-09578-6

Czeisler, M. É., Lane, R. I., Wiley, J. F., Czeisler, C. A., Howard, M. E., \& Rajaratnam, S. M. W. (2021). Follow-up survey of US adult reports of mental health, substance use, and suicidal ideation during the COVID-19 Pandemic, September 2020. JAMA Network Open, 4(2), e2037665. https://doi.org/10. 1001/jamanetworkopen.2020.37665 
Daly, M., Sutin, A. R., \& Robinson, E. (2020). Longitudinal changes in mental health and the COVID-19 Pandemic: Evidence from the UK Household Longitudinal Study. Psychological Medicine. https://doi.org/10.1017/s00332917200044 32

Estévez-Soto, P. R. (2021). Crime and COVID-19: effect of changes in routine activities in Mexico City. Crime Science, 10(1), 15. https://doi.org/10.1186/ s40163-021-00151-y

Felson, M., Jiang, S., \& Xu, Y. (2020). Routine Activity Effects of the Covid-19 Pandemic on Burglary in Detroit, March 2020. Crime Science, 9(1), 10. https://doi. org/10.1186/s40163-020-00120-x

Fitzpatrick, K. M., Harris, C., \& Drawve, G. (2020). Fear of COVID-19 and the Mental Health Consequences in America. Psychological Trauma: Theory, Research, Practice, and Policy, 12(S1), S17-S21. https://doi.org/10.1037/tra0000924

Frederick, T., O'Connor, C., \& Koziarski, J. (2018). Police Interactions with People Perceived to have a Mental Health Problem: A Critical Review of Frames, Terminology, and Definitions. Victims \& Offenders, 13(8), 1037-1054. https://doi.org/10.1080/15564886.2018.1512024

Gerell, M., Kardell, J., \& Kindgren, J. (2020). Minor Covid-19 Association with Crime in Sweden. Crime Science, 9(1), 19. https://doi.org/10.1186/ s40163-020-00128-3

Hodgkinson, T., \& Andresen, M. A. (2020). Show me a man or a woman alone and $i^{\prime} l l$ show you a saint: Changes in the frequency of criminal incidents during the COVID-19 Pandemic. Journal of Criminal Justice, 69, 101706. https://doi. org/10.1016/j.jcrimjus.2020.101706

Holman, E. A., Thompson, R. R., Garfin, D. R., \& Silver, R. C. (2020). The Unfolding COVID-19 Pandemic: A probability-based, nationally representative study of mental health in the United States. Science Advances, 6(42), eabd5390. https://doi.org/10.1126/sciadv.abd5390

Jenkins, E. K., McAuliffe, C., Hirani, S., Richardson, C., Thomson, K. C., McGuinness, L., Morris, J., Kousoulis, A., \& Gadermann, A. (2021). A Portrait of the Early and Differential Mental Health Impacts of the COVID-19 Pandemic in Canada: Findings from the first wave of a nationally representative cross-sectional survey. Preventive Medicine, 145, 106333. https://doi.org/10.1016/j.ypmed. 2020.106333

Khademi, M., Vaziri-Harami, R., \& Shams, J. (2021). Prevalence of mental health problems and its associated factors among recovered COVID-19 Patients during the pandemic: a single-center study. Frontiers in Psychiatry, 12, 602244. https://doi.org/10.3389/fpsyt.2021.602244

Kock, J. H. D., Latham, H. A., Leslie, S. J., Grindle, M., Munoz, S.-A., Ellis, L., Polson, R. \& O'Malley, C. M. (2021). A rapid review of the impact of COVID-19 on the mental health of healthcare workers: Implications for supporting psychological well-being. BMC Public Health, 21(1), 104. https://doi.org/10.1186/ s12889-020-10070-3

Koziarski, J., \& Huey, L. (2021). Defund or Re-fund? Re-examining Bayley's Blueprint for Police Reform. International Journal of Comparative and Applied Criminal Justice. https://doi.org/10.1080/01924036.2021.1907604

Langton, S., Dixon, A., \& Farrell, G. (2021). Six Months in Pandemic Crime Trends in England and Wales. Crime Science, 10(1), 6. https://doi.org/10.1186/ s40163-021-00142-z

Lersch, K. M. (2020). COVID-19 and Mental Health: An Examination of 911 Calls for Service. Policing: A Journal of Policy and Practice, 14(4), paaa049. https://doi. org/10.1093/police/paaa049

Linning, S. J., Andresen, M. A., \& Brantingham, P. J. (2017). Crime Seasonality: Examining the temporal fluctuations of property crime in cities with varying climates. International Journal of Offender Therapy and Comparative Criminology, 61(16), 1866-1891. https://doi.org/10.1177/0306624×16632259

Lum, C., Koper, C. S., \&Wu, X. (2021). Can We Really Defund the Police? A NineAgency Study of Police Response to Calls for Service. Police Quarterly. https://doi.org/10.1177/10986111211035002

Moitra, M., Rahman, M., Collins, P.Y., Gohar, F., Weaver, M., Kinuthia, J., Rössler, W., Petersen, S., Unutzer, J., Saxena, S., Huang, K. Y., Lai, J., \& Kumar, M. (2021). Mental Health Consequences for Healthcare Workers During the COVID-19 Pandemic: A Scoping Review to Draw Lessons for LMICs. Frontiers in Psychiatry, 12, 602614. https://doi.org/10.3389/fpsyt.2021.602614

Moreno, C., Wykes, T., Galderisi, S., Nordentoft, M., Crossley, N., Jones, N., Cannon, M., Correll, C. U., Byrne, L., Carr, S., Chen, E. Y. H., Gorwood, P., Johnson, S., Kärkkäinen, H., Krystal, J. H., Lee, J., Lieberman, J., López-Jaramillo, C., Männikkö, M., \& Arango, C. (2020). How Mental Health Care Should Change as a Consequence of the COVID-19 Pandemic. The Lancet Psychiatry, 7(9), 813-824. https://doi.org/10.1016/s2215-0366(20)30307-2
Mosheva, M., Gross, R., Hertz-Palmor, N., Hasson-Ohayon, I., Kaplan, R., Cleper, R., Kreiss, Y., Gothelf, D., \& Pessach, I. M. (2021). The Association between Witnessing Patient Death and Mental Health Outcomes in Frontline COVID-19 Healthcare Workers. Depression and Anxiety, 38(4), 468-479. https://doi.org/ $10.1002 / d a .23140$

Nielsen, K. (2020). A Timeline of COVID-19 in Ontario. Global News. Available at: https://globalnews.ca/news/6859636/ontario-coronavirus-timeline/

Payne, J. L., Morgan, A., \& Piquero, A. R. (2021). Exploring Regional Variability in the Short-Term Impact of COVID-19 on Property Crime in Queensland Australia. Crime Science, 10(1), 7. https://doi.org/10.1186/s40163-020-00136-3

Pfefferbaum, B., \& North, C. S. (2020). Mental Health and the Covid-19 Pandemic. New England Journal of Medicine, 383(6), 510-512. https://doi.org/10.1056/ nejmp2008017

Piquero, A. R., Jennings, W. G., Jemison, E., Kaukinen, C., \& Knaul, F. M. (2021). Evidence from a Systematic Review and Meta-Analysis Domestic Violence during the COVID-19 Pandemic. Journal of Criminal Justice, 74, 101806. https://doi.org/10.1016/j.jcrimjus.2021.101806

Proto, E., \& Quintana-Domeque, C. (2021). COVID-19 and Mental Health Deterioration by Ethnicity and Gender in the UK. PLOS ONE, 16(1), e0244419. https:// doi.org/10.1371/journal.pone.0244419

Rajkumar, R. P. (2020). COVID-19 and Mental Health: A Review of the Existing Literature. Asian Journal of Psychiatry, 52, 102066. https://doi.org/10.1016/j. ajp.2020.102066

Ratcliffe, J. H. (2021). Policing and Public Health Calls for Service in Philadelphia. Crime Science, 10(1), 5. https://doi.org/10.1186/s40163-021-00141-0

Rossi, R., Socci, V., Talevi, D., Mensi, S., Niolu, C., Pacitti, F., Marco, A. D., Rossi, A., Siracusano, A., \& Lorenzo, G. D. (2020). COVID-19 Pandemic and Lockdown Measures Impact on Mental Health Among the General Population in Italy. Frontiers in Psychiatry, 11, 790. https://doi.org/10.3389/fpsyt.2020.00790

Thompson, S. (2010). Policing Vancouver's Mentally Ill: The Disturbing Truth. https://vancouver.ca/police/assets/pdf/reports-policies/vpd-lost-in-trans ition-part-2-draft.pdf

Vahratian, A., Blumberg, S. J., Terlizzi, E. P., \& Schiller, J. S. (2021). Symptoms of Anxiety or Depressive Disorder and Use of Mental Health Care Among Adults During the COVID-19 Pandemic — United States, August 2020-February 2021. Morbidity and Mortality Weekly Report, 70(13), 490-494. https://doi.org/ 10.15585/mmwr.mm7013e2

Vaughan, A. D., Hewitt, A. N., Hodgkinson, T., Andresen, M. A., \& Verdun-Jones, S. (2019). Temporal Patterns of Mental Health Act Calls to the Police. Policing: A Journal of Policy and Practice, 13(2), 172-185. https://doi.org/10. 1093/police/pay060

Vigo, D., Patten, S., Pajer, K., Krausz, M., Taylor, S., Rush, B., Raviola, G., Saxena, S., Thornicroft, G., \& Yatham, L. N. (2020). Mental Health of Communities during the COVID-19 Pandemic. The Canadian Journal of Psychiatry, 65(10), 681-687. https://doi.org/10.1177/0706743720926676

Vindegaard, N., \& Benros, M. E. (2020). COVID-19 Pandemic and Mental Health Consequences: Systematic Review of the Current Evidence. Brain, Behavior, and Immunity, 89, 531-542. https://doi.org/10.1016/j.bbi.2020.05.048

Wang, C., Pan, R., Wan, X., Tan, Y., Xu, L., McIntyre, R. S., Choo, F. N., Tran, B., Ho, R., Sharma, V. K., \& Ho, C. (2020). A Longitudinal Study on the Mental Health of General Population during the COVID-19 Epidemic in China. Brain, Behavior, and Immunity, 87, 40-48. https://doi.org/10.1016/j.bbi.2020.04.028

Wang, Y., Shi, L., Que, J., Lu, Q., Liu, L., Lu, Z., Xu, Y., Liu, J., Sun, Y., Meng, S., Yuan, K., Ran, M., Lu, L., Bao, Y., \& Shi, J. (2021). The Impact of Quarantine on Mental Health Status among General Population in China during the COVID-19 Pandemic. Molecular Psychiatry. https://doi.org/10.1038/s41380-021-01019-y

Watson, A. C., Pope, L. G., \& Compton, M. T. (2021). Police Reform From the Perspective of Mental Health Services and Professionals: Our Role in Social Change. Psychiatric Services, appi.ps.2020005. doi:https://doi.org/10.1176/ appi.ps.202000572

Wilson-Bates, F. (2008), Lost in Translation: How a Lack of Capacity in the Mental Health System is Failing Vancouver's Mentally III and Draining Police Resources. https://vancouver.ca/police/assets/pdf/reports-policies/vpdlost-intransition-part-2-draft.pdf

World Health Organization (2020). WHO Director-General's Opening Remarks at the Media Briefing on COVID-19 - 11 March 2020. World Health Organization. Available at: https://www.who.int/director-general/speec hes/detail/who-director-general-s-opening-remarks-at-the-media-brief ing-on-covid-19---11-march-2020 
Wuschke, K. E., Andresen, M. A., Brantingham, P. J., Rattenbury, C., \& Richards, A. (2017). What Do Police Do and Where Do They Do It? International Journal of Police Science \& Management, 20(1), 19-27. https://doi.org/10.1177/14613 55717748973

Xiong, J., Lipsitz, O., Nasri, F., Lui, L. M. W., Gill, H., Phan, L., Chen-Li, D., lacobucci, M., Ho, R., Majeed, A., \& McIntyre, R. S. (2020). Impact of COVID-19 Pandemic on Mental Health in the General Population: A Systematic Review. Journal of Affective Disorders, 277, 55-64. https://doi.org/10.1016/j.jad.2020.08.001

Zajacova, A., Jehn, A., Stackhouse, M., Choi, K. H., Denice, P., Haan, M., \& Ramos, H. (2020). Mental Health and Economic Concerns from March to May during the COVID-19 Pandemic in Canada: Insights from an Analysis of Repeated Cross-Sectional Surveys. SSM - Population Health, 12, 100704. https://doi.org/ 10.1016/j.ssmph.2020.100704

\section{Publisher's Note}

Springer Nature remains neutral with regard to jurisdictional claims in published maps and institutional affiliations. 